\title{
pro.posições
}

\section{Um olhar sobre desafios da gestão didático-pedagógica no Ensino Superior ${ }^{1}$}

\section{A perspective on the challenges of didactic and pedagogical management in Higher Education}

\begin{abstract}
* Departamento de Administração Escolar e Planejamento Educacional; Programa de pós-graduação em Educação; Centro de Educação; Universidade Federal de Pernambuco - UFPE, Recife, PE, Brasil. carrilho1513@gmail.com
\end{abstract}

Resumo
Tratar da gestão na Educação Superior remete a considerar princípios que vêm
fundamentando políticas no âmbito da relação de indissociabilidade institucional-
pedagógica nesse nível de ensino. Nessa direção, o presente texto versa sobre a
possibilidade de um lugar de ensino sistematizado que leve em conta questões de
ordem didático-pedagógica na gestão no Ensino Superior, refletindo sobre a
relação institucional-pedagógica nesse cenário. O estudo tem como foco a
compreensão de que uma gestão democrática se concretiza a partir das tensões e
dos conflitos presentes no cotidiano. Por um lado, a gestão nesse contexto
evidencia demandas apresentadas aos docentes que atuam no setor público,
decorrentes de exigências dos processos avaliativos que trazem como
consequência ações de produtividade as quais vêm acarretando a intensificação do
trabalho docente. E, por outro lado, ela indicia possibilidades de alargar uma
atuação colegiada nos processos decisórios dos rumos da gestão no Ensino
Superior.
Palavras-chave: Educação Superior, gestão no Ensino Superior, projeto
pedagógico

1 CAPES - Coordenação de Aperfeiçoamento de Pessoal de Nível Superior 


\section{pro.posıções}

\section{Abstract}

Dealing with management in higher education refers to consider principles that are justifying politics within the institutional and pedagogical inseparability relation in Higher Education. In addition, the present research deals with the outline of a place for didactic and pedagogical order issuesin the management of higher education, reflecting about the institutional and pedagogical relation of management in this scenario. Moreover, it focuses on the comprehension that a democratic management comes true in the tensions and conflicts present in daily life. On one hand, contextualizing demands presented to professors that work in the public sector thanks to the evaluation processes requirements that brings as a consequence the productive actions, which are resulting in an intensification of the teaching work. And, on the other hand, indicating possibilities to widen a collegiate action in the decision processes of the higher education management paths.

Keywords: higher education, management in bigher education, pedagogical project

\section{Reflexão sobre a relação institucional-pedagógica na gestão do Ensino Superior}

A história nos instiga à busca de explicações para os problemas na organização e na gestão da universidade tanto no âmbito político-institucional como no do cotidiano. Os recentes esforços para a reforma na gestão pedagógica da Educação Superior revelam considerando-se reflexões de Sander (2005) sobre gestão - que as tomadas de decisões administrativas ainda estão voltadas prioritariamente para fins pragmáticos e resultados imediatos (sem levar em consideração a questão da ética e da relevância cultural) com o intuito de "aumentar a produtividade e a eficiência econômica na prestação de serviços, independentemente de seu significado substantivo para a população” (p. 109).

Entretanto, incorporando a diversidade e a complexidade dos vários reforços, a preocupação de implementar reformas teria a ver com parte da estratégia global, ou seja, com a governabilidade que busca interceder estrategicamente a fim de atender às complexas e delicadas relações dos governantes e dos empresários com a sociedade civil e as instituições sociais que representam a vida moderna (Sander, 2005). 


\section{pro.posições}

Nesse sentido, o que se apreende é que a globalização, conforme Maltez (2003), "não é fatalidade nem utopia, não é o demônio do mal absoluto nem o deus do bem, dado que não consegue captar-se pelos métodos desse pensamento binário que está na origem das ideologias" (p. 100).

Rámirez (2011) refere-se com maestria a essa questão aplicada à esfera educacional, quando afirma que "a educação não é apenas um dos fatores mais importantes que contribuem para o desenvolvimento social e econômico das nações, como também um dos maiores setores da economia mundial"' (p. 25).

Nesse trânsito, as modificações no âmbito da Educação Superior, registradas até a década de 90 do século passado, revelam que, durante muitos anos, elas se limitaram à organização dos currículos, à capacitação dos professores e ao acompanhamento das ações rotineiras.

Ou seja, de acordo com Sousa (2011), “o trabalho voltava-se aos aspectos pedagógicos, e os gestores não se envolviam nas demais questões que constituem o universo de uma instituição de educação superior, como os aspectos financeiros, de planejamento e de organização administrativa" (p. 97). Desse modo, para tratar da gestão pedagógica na Educação Superior, é necessário estabelecer uma relação de indissociabilidade com a gestão institucional.

A gestão da educação brasileira, independente da origem etimológica e de várias estimativas conceituais e praxiológicas, se instalou no Brasil como um conceito que se atrela ao pensar e ao fazer educação em sua totalidade, com a finalidade de cumprir sua missão política e cultural, visando alcançar seus objetivos pedagógicos (Sander, 2005).

No contexto desse propósito, Sander (2005) afirma que:

a gestão da educação abarca desde a formulação de políticas, planos institucionais e a concepção de projetos pedagógicos para os sistemas educacionais e as instituições escolares até a execução, a supervisão e a avaliação institucional das atividades de ensino, pesquisa e extensão e a administração dos recursos financeiros, materiais e tecnológicos. (p.127)

Essa definição de gestão da educação apresentada por Sander (2005) aproxima-se dos conceitos de governo, governação ou governança, ainda hoje muito usados na educação. Em consonância com essa definição, desenvolvem-se as funções pedagógicas específicas nas instituições de ensino - previstas na Constituição Federal de 1988 (Constituição BR, 1988), na 


\section{pro.p̣osıções}

Lei de Diretrizes e Bases da Educação Nacional no 9.394/96 (Lei BR, 1996), nas Diretrizes Curriculares Nacionais de 2006 (Resolução CNE/CP, 2006) e em outros documentos legais.

Diante desse quadro, atualmente se identificam duas vertentes educacionais, as quais mobilizaram forças na produção do conhecimento no campo da política e do governo. Conforme Sander (2005), "trata-se do enfoque produtivo, voltado para o mercado, e do enfoque democrático, voltado para a cidadania" [itálico adicionado] (p. 128).

A tendência democrática na educação brasileira é patente na legislação do ensino, nas práticas de gestão educacional e na produção acadêmica das assembleias de educadores. No dizer de Sander (2005), a efetivação da gestão democrática da educação apresenta um desafio de grandes proporções, pois implica uma filosofia política e uma estratégia de ação pedagógica. Torna-se indispensável, portanto, oportunizar educação cidadã, de trabalho e aprendizado coletivos, buscando desenvolver uma participação ativa no pensar e no fazer a educação, no intuito de promover estratégias de ação humana coletiva na formação e na execução de políticas para a educação.

A prática democrática requer essencialmente o desenvolvimento e o aperfeiçoamento de todos que atuam na instituição, no sentido de que compreendam a complexidade do trabalho pedagógico e a importância da contribuição individual e coletiva para sua realização.

A gestão democrática carece ser compreendida como um objetivo a ser sempre perseguido e aperfeiçoado, além de se configurar como uma prática habitual nos espaços educativos (Bordignon \& Gracindo, 2001).

Veiga (1996) alerta, ainda, que "a gestão democrática exige a compreensão em profundidade dos problemas postos pela prática pedagógica. Ela visa a romper a separação entre o pensar e o fazer, entre teoria e prática (p. 18)".

Destacamos também que a capacidade de gestão não se institui de imediato. Implica processo de aprendizagem de equipe e condições institucionais mínimas. Dentre essas condições, destacam-se: equipe de docentes; definição clara dos objetivos; acompanhamento e avaliação das ações descentralizadas; planejamento; solução de problemas; e tomadas de decisão de forma compartilhada (Lopes Filho, 1992).

Paro (1998) ressalta que a participação democrática é imbuída dos efeitos da ideologia, por meio das concepções e das crenças enraizadas, historicamente, na personalidade de cada 


\section{pro.posıções}

indivíduo, uma vez que essas visões de mundo movem suas práticas e seus comportamentos na relação com os outros. Assim, é preciso considerar a dimensão em que o modo de pensar e de agir dos indivíduos facilita, incentiva, dificulta ou impede a participação de todos.

A participação em seu sentido pleno caracteriza-se pelo poder de atuação consciente, em que se delibera e se atua com competência e com vontade de compreender o dia a dia. No entanto, para se fazer algo consciente e com convicção, é necessária também a reflexão crítica, individual e coletiva fundamentada no devido respaldo teórico.

Diante desse cenário, o movimento de incorporação da dimensão didático-pedagógica contribui para a superação de posturas amadoras na gestão e nos processos organizacionais da universidade. E ressaltamos ainda que essa incorporação é um importante passo no processo de reconhecimento do caráter multidimensional do trabalho administrativo e na efetivação de uma postura democrática.

Por tal razão, faz-se necessário compreender que a gestão pedagógica na Educação Superior se define a partir das políticas institucionais assumidas, ou seja, se organiza de acordo com a missão, as crenças e os valores estabelecidos por quem idealizou e implantou seu funcionamento (Sousa, 2011).

Isso porque "as crenças e os valores definidos contemplam o que deve ser prioridade na IES [Instituição de Ensino Superior] e tornam-se consolidados quando são observados na prática dos profissionais, sejam eles gestores, professores ou colaboradores” (p. 99). Ou seja, no contexto desse entendimento, as pessoas que fazem parte também dos recursos da IES, que incluem os equipamentos, os recursos financeiros e tecnológicos, etc.

Nesse caso, o que garante a efetividade da equipe multiprofissional é a formação de todos que nela atuam - isto é, diretores, coordenadores e professores - para tomar decisões conciliáveis com o projeto pedagógico definido pela IES.

Assim, interessa ressaltar aqui que o trabalho docente na Educação Superior se depara com várias tensões, uma das quais é a formação específica da docência nesse nível de ensino, cuja legislação se apresenta pouco específica nesse caso. Outro aspecto se constitui na diversidade de demandas exigidas a esses professores que atuam como gestores, coordenadores e chefias, no setor público, o que acarreta a intensificação do trabalho docente. Não podemos nos esquecer, também, da participação nos programas de pós-graduação, que trazem consigo as exigências dos processos avaliativos, além da consequente demanda de 


\section{pro.posições}

produtividade. Essa sobrecarga muitas vezes impossibilita a atuação de forma adequada na graduação e torna-a indesejável.

É preciso considerar que o desenvolvimento profissional influencia e é influenciado pelo contexto organizacional em que acontece. Alternativas para aperfeiçoar esse contexto organizacional seriam a criação de políticas e programas de formação, a melhoria das condições do trabalho docente e uma maior organização do trabalho pedagógico.

\section{Procedimentos organizacionais na Educação Superior}

A lei de Diretrizes e Bases da Educação (LDB), no 9.394/96, de 20 de dezembro de 1996, reserva o capítulo IV (Art. 43 a 57) para a Educação Superior. De acordo com esse documento, o Ensino Superior se caracteriza por algumas especificidades, dentre as quais a que destina à União a competência para estabelecer as normas para esse nível de ensino.

A Educação Superior, segundo essa lei, tem por finalidade:

I - estimular a criação cultural e o desenvolvimento do espírito científico [itálico adicionado] e do pensamento reflexivo;

III - incentivar o trabalho de pesquisa [itálico adicionado] e investigação científica, visando ao desenvolvimento da ciência e da tecnologia, da criação e difusão da cultura, e, desse modo, desenvolver o entendimento do homem e do meio em que vive;

VII - promover a extensão [itálico adicionado], aberta à participação da população, visando à difusão das conquistas e benefícios resultantes da criação cultural e da pesquisa científica e tecnológica geradas na instituição. (Lei BR, 1996)

Como forma de regulamentar e operacionalizar o que está posto na Lei 9.394/96, ela promove a descentralização e a autonomia para as universidades, além de instituir um processo regular de avaliação do ensino das instituições (Art. 46).

Destacamos, ainda, regras e normas contidas no artigo 12, inciso 1, que prescreve: "os estabelecimentos de ensino, respeitadas as normas comuns e as de seu sistema de ensino, terão a incumbência de elaborar e executar sua proposta pedagógica”.

Nas determinações legais e normativas que incidem sobre a gestão, o Art. 56, da LDB 9.394/96 é autoexplicativo: “as instituições públicas de educação superior obedecerão ao 


\section{pro.posıções}

princípio da gestão democrática, assegurada a existência de órgãos colegiados deliberativos, de que participarão os segmentos da comunidade institucional, local e regional”.

Compreendendo esse movimento de construção e reconstrução - permeado por tensões e contradições que estão na gênese das mudanças que a universidade vem vivenciando e que interferem na gestão -, uma IES tem normas e princípios específicos que os docentes precisam dominar para exercer todas as atividades que lhes são solicitadas. Assim, segundo Carneiro (2010), “inteirar-se de tudo isso exige tempo e dedicação (p. 103)”. Nesse contexto, a prática do cotidiano exige tempo e mobilização de saberes construídos no dia a dia.

Concordando com Carneiro (2010), podemos citar como exemplo de atividades:

a análise dos mais diversos processos e a redação de pareceres: ascensão profissional de pares, análise de currículos, equivalência de disciplinas, de diplomas de cursos de graduação e de pósgraduação, entre outros. Para desempenhar esse papel, faz-se necessário um estudo detalhado da legislação que, por sua vez, muda constantemente para atender às exigências da sociedade e da própria instituição. Onde aprende tudo isso? Aprende-se tudo isso fazendo! (p.103)

Diante dessa situação, buscamos refletir sobre a política para o Ensino Superior no âmbito da pós-graduação. A criação dos Programas de Pós-Graduação nas universidades brasileiras, no contexto atual, é fruto da modernização conservadora do Ensino Superior, realizada a partir do trabalho típico dos governos militares (Nosella, 2010). Assim, é preciso situar a verificação do desempenho acadêmico, que se tornou obrigatória a partir de 1985, século passado, estando em vigor até os dias atuais.

Recorremos novamente a Nosella (2010), quando ela afirma que "o retorno da democracia no país, a crise dos paradigmas teóricos, a expansão dos Programas de PósGraduação em Educação e a explosão do ensino superior privado representaram as condições remotas dessa cultura" (p. 537). Essas condições buscam ações, organizadas por cada instituição, que visam promover o desenvolvimento profissional dos docentes.

Nessa perspectiva, a difusão dos Programas de Pós-Graduação em Educação nas universidades marcou o início das atividades de pesquisa e da produção acadêmica por meio da sua institucionalização e burocratização. Assim "a escolarização da produção acadêmica burocratizou o trabalho científico, enfatizando o aspecto quantitativo formal. Como se sabe, o burocratismo acadêmico nivela, pelos títulos e diplomas, pesquisas de qualidade com outras menos significativas" (p. 538). 


\section{pro.posıções}

Em síntese, a crise dos paradigmas, a institucionalização dos estudos e as pesquisas na área educacional deram origem ao alastramento da cultura do desempenho. Nesse sentido, a Coordenação de Aperfeiçoamento de Pessoal de Nível Superior (CAPES) é reconhecida não mais como instituição que foi criada e dirigida para a formação dos quadros docentes do Ensino Superior, mas como instituição de avaliação e "ranqueamento" escolar.

Outro aspecto relevante, apontado por Nosella (2010), é que a cultura do desempenho transformou os docentes de atores principais da educação em "executores apressados, angustiados e culpados, cabendo a estes reivindicarem com coragem seu espaço de significação, de competência e autonomia" (p. 542).

$\mathrm{Na}$ realidade, a falta de autonomia setorial diz respeito às regras de produção acadêmica originárias de áreas diferentes das humanas e impostas como garantia absoluta de qualidade científica. Devemos entender a docência, então, não como mera aplicação de técnicas, nem como imitação automática de experiências e métodos, mas como um ato pedagógico crítico, voltado para a aprendizagem dos estudantes e dos docentes.

Considerando o dizer de Casagrande (2011), a avaliação institucional é um caminho para que as IES conheçam a si mesmas e a seus concorrentes. No entanto, enfatizamos que as questões legais estão respaldadas em políticas de governo, dessa maneira, o gestor precisa examinar com atenção os limites impostos pelo próprio sistema.

Como em qualquer ato avaliativo, conforme Luckesi (2011), “a compreensão e a experiência do outro, ou dos outros, podem ser nossos aliados em nossa jornada de busca e aprendizagem do ato de avaliar. ... O que posso efetivamente aplicar do que aprendo ouvindo dos outros? Estou aberto para tentar isso?” (pp. 31-32).

O modo de ensinar, de aprender e de avaliar muitas vezes está enraizado nas nossas crenças, nos nossos valores e nos sentidos e significados que construímos tanto em nossa vida pessoal quanto na acadêmica e profissional.

Diante do exposto, percebemos a ausência de políticas educacionais explícitas, o que pode decorrer da falta de compreensão em relação à finalidade que se pretende atingir com o ensino universitário.

Por conseguinte, a docência acaba sendo algo solitário, quando deveria ser compartilhada. O professor passa por um concurso público para assumir a docência em uma 


\section{pro.posıções}

universidade pública; entretanto, de repente, encontra-se envolvido com a gestão no contexto universitário. Ocorre que, de forma geral, muitos não se percebem preparados suficientemente para as atividades gestoras.

De acordo com uma afirmação de Kanan e Zanelli (2011), tem sido prática recorrente

que, para compreender o envolvimento com o trabalho e, de forma geral, o sentido e significado do trabalho para os docentes-gestores, é necessário compreender a ação mediadora realizada pelos demais atores presentes no processo de apropriação dos resultados da prática social nesse contexto. (p. 57)

Ainda que existam propostas construídas pelas IES, elas continuam distanciadas da realidade. Isso porque essas instituições públicas, de acordo com Dias (2010), "não ficam imunes aos percalços decorrentes das políticas administrativas de sucessivas gestões do governo federal que comprometem sensivelmente sua capacidade econômica, inviabilizando a construção e a implementação de programas de qualificação e aperfeiçoamento de seus recursos humanos, técnico-administrativos e docentes" (p.77).

Tais exigências evidenciam a escassez de programas institucionais articulados, principalmente considerando que o compromisso da universidade é com a transformação da sociedade por meio da construção democrática de convivência humana. É importante também compreender como ocorre a avaliação dos seus processos. Isso requer, segundo Kanan e Zanelli (2011), a consolidação de uma perspectiva que se baseia nas pessoas e em seus valores, possibilitando, assim, uma ação capaz de transformar as relações que ora vigoram.

Entretanto, o cotidiano das instituições força respostas rápidas para atender aos desafios contemporâneos e à necessidade de rever posturas amadoras na gestão e nos processos organizacionais. Assim entendemos como desafiador e oportuno, para a comunidade docente universitária, um conhecimento sobre gestão que possibilite a reflexão sobre a cultura, sobre as experiências e sobre a realidade nacional.

Tratar da gestão sob a ótica dos processos organizacionais, considerando a prática cotidiana, é uma necessidade. Isto implica compreender o processo de gerenciamento, que deve ser identificado e definido como um agente administrador para que assuma um papel significativo na relação interpessoal e em todo o processo pedagógico. 


\section{pro.posições}

Diante de todo esse contexto, Morin (1997) chama atenção, ao afirmar que as políticas influenciam e podem marcar, por meio de seus princípios e valores, uma organização que, a princípio, é por natureza institucional.

Trazer, portanto, a vivência na Coordenação do Curso de Pedagogia e na Chefia de Departamento como elemento que consolida a gestão institucional denota a importância das decisões, das normas, das discussões do Colegiado $^{2}$ e do Conselho Departamental ${ }^{3}$, que têm a responsabilidade de dar suporte ao trabalho pedagógico e às ações emanadas do sistema universitário. No entanto, é importante destacar, ainda, que todo processo de tomada de decisão é coletivo, e cada membro cumpre a sua função, participando, assim, da construção do Ensino Superior.

\section{O didático-pedagógico no Ensino Superior}

O processo de construção de novos significados nas políticas das IES não pode deixar de considerar que - como nos mostra a história da universidade - elas têm sido respaldadas, predominantemente, pelo conservadorismo, pelo individualismo, pelo clientelismo e pelo autoritarismo, o que mantém a universidade no estatuto de lugar privilegiado de produção e difusão do conhecimento.

As transformações que vêm ocorrendo desde meados do século passado, devido ao processo de transição política e ao retorno da democracia no Brasil, começam a impulsionar, por parte do Ensino Superior, uma redefinição com vistas a um desenvolvimento que justifique a manutenção do seu lugar de prestígio na produção e na difusão do conhecimento.

Esse contexto de transição político-social vem afetando a universidade, fazendo com que ela reveja a forma como o conhecimento vem sendo construído, assim como as relações que se estabelecem em sala de aula.

Dos professores universitários na sociedade atual exige-se, segundo Ramos (2010), a compreensão de reconstruir a docência, inserida num processo de redefinição identitária da

2 O Colegiado é a instância deliberativa de um curso de graduação na Universidade Federal de Pernambuco (UFPE). No caso acima referenciado, é composto pelo Coordenador e Vice-Coordenador do Curso de Pedagogia e pelo conjunto de dois docentes de cada departamento do Centro de Educação da UFPE.

3 O Conselho Departamental é o locus privilegiado de decisões de um centro na UFPE, congregando representantes de todos os setores (Direção, Coordenações, Departamentos, Funcionários e Estudantes). 


\section{pro.posıções}

universidade, especificamente no que diz respeito à transição para uma nova maneira de produzir conhecimento, que aponte "para uma necessária consideração da complexidade das questões pedagógico-didáticas neste lócus” (p. 36).

Pelo exposto, fica patente que a universidade, até o início do século XXI, embora tenha convivido com concepções e modelos distintos, não se viu na obrigação de discutir acerca do ensino e da aprendizagem nela desenvolvidos, sobretudo no que diz respeito aos seus fundamentos e à reflexão didático-pedagógica. Isso se deve, como afirma Ramos (2010), à "característica marcante de corporação centrado no mestre"(p. 36). Portanto, ficava impossível questionar tal processo, pois, ainda segundo a autora, "soaria como duvidar da autoridade docente. Dentro desta lógica, justificava-se a visão de que quem sabe, automaticamente, sabe ensinar" [itálico adicionado] (p. 36).

Ao se preservar a universidade como espaço de produção e difusão do saber, mantémse uma maneira, conforme Ramos (2010), de conceber a docência como "diversa em seu aspecto de destaque, mas redutível à figura do docente e ao ensino pela própria característica desta ideia de universidade" (p. 37).

Assim, segundo Cunha (1998), se a docência é por primazia articuladora “do paradigma de ensinar e de aprender na Universidade" (p. 15), questiona-se em que aspectos tem recaído a crítica à forma centralizadora do ensino e quais argumentos têm sido propostos para a busca de um conhecimento profissional docente.

No que diz respeito a essas questões, Zabalza (2007) chama atenção para um dos dilemas vividos pelos docentes universitários: mudar o foco da formação no ensino para a formação na aprendizagem. Ou seja, "o importante não é o que se fale ou explique bem os conteúdos: o importante é como eles são entendidos, organizados e integrados em um conjunto significativo de conhecimentos e habilidades novas" (p. 156).

Como afirma Behrens (2005), os docentes universitários na atualidade, estão subdivididos em quatro categorias:

1) os professores das várias áreas do conhecimento que se dedicam à docência em tempo integral; 2) os profissionais que atuam no mercado de trabalho específico e se dedicam ao magistério algumas horas por semana; 3) os profissionais docentes da área pedagógica e das licenciaturas que atuam na universidade, e paralelamente no ensino básico; 4) os profissionais da área da educação e das licenciaturas que atuam em tempo integral na universidade (p. 57). 


\section{pro.posıções}

Tendo em vista essas categorias, o perfil do docente universitário encontra-se bem diversificado, o que constitui um desafio para os cursos de formação.

Diante desse quadro, no que se refere às formações universitárias, são exigidas do docente universitário no contexto atual ações em movimento contínuo. Ou seja, segundo Leite e Silva (1991), cada um é “um ser que 'está sendo’ [ênfase adicionada] e se está transformando em função da própria dinâmica de existir” (p. 329).

Tendo por base essa concepção, Zabalza (2007, p. 111) enfatiza, ainda, que ensinar é uma tarefa complexa na medida em que exige um conhecimento consistente da disciplina ou das atividades, bem como da maneira como os estudantes aprendem.

Os anúncios da democratização da universidade, sua expansão, interiorização, ampliação de vagas e, consequentemente, a necessidade de contratação de novos professores têm evidenciado a complexidade da docência na universidade.

A esse respeito Bazzo (2005) traz suas contribuições, quando considera que

a recente expansão dos contingentes universitários e sua consequente diversificação e heterogeneidade advindas das novas regulações que preveem o ingresso por cotas de estudantes das escolas públicas e por etnias vêm acrescentar mais um ingrediente importante à discussão de como enfrentar a problemática da gestão da formação dos professores do Ensino Superior. (p.12)

\section{Para concluir}

Ao se discorrer sobre a temática do olhar sobre desafios da gestão didático-pedagógica no Ensino Superior,

diz-se que as instituições não devem limitar-se a responder aos problemas: devem, de fato, construir um projeto capaz de enfrentar tanto os ajustes a serem incorporados visando a melhor adaptação às mudanças como as novas expectativas e ideias que refletem o sentimento dos diversos setores envolvidos. (Zabalza, 2007, p. 104)

Enfim, uma política institucional deve incidir na implantação de um conjunto de atuações em todas as esferas da instituição. O que se apreende desse contexto instável é que distintos interesses têm movido mudanças que exigem a implantação de políticas de formação 


\section{pro.posıções}

e de gestão que estabeleçam compromisso com as universidades, embora sejam difíceis de serem operacionalizadas.

Consideramos, assim, que a docência universitária engloba sujeitos essencialmente diferentes, que estão no confronto e na conquista do conhecimento. Desse modo, para desenvolvê-la, é de essencial relevância o conhecimento da realidade que os cerca. Ou seja, é imprescindível a efetivação de uma investigação dos problemas existentes na instituição, para que essa realidade seja discutida coletivamente a fim de elaborar um plano de propostas e encaminhamentos para ser posto em ação.

Os desafios da gestão didático-pedagógica no Ensino Superior requerem, por um lado, contextualizar demandas apresentadas aos docentes que atuam no setor público, decorrentes de exigências dos processos avaliativos. Esses processos, por sua vez, trazem como consequência excessivas demandas de produtividade, o que vem acarretando a intensificação do trabalho docente. Por outro lado, indiciam possibilidades de desenvolver uma ação colegiada - nomeadamente por meio da assunção da responsabilidade coletiva nos processos decisórios dos rumos da gestão no Ensino Superior. 


\section{pro.posıções}

ISSN 1980-6248

\section{Referências Bibliográficas}

Bazzo, V. L.(2005). Uma experiência de formação para professores do ensino superior. UFSC, Santa Catarina. Reunião Anual da ANPED - GT 11: Política de Educação Superior, GT 11, 01-18.

Behrens, M. A. (2005). O paradigma emergente e a prática pedagógica. Petrópolis: Vozes.

Bordignon, G., \& Gracindo, R. V. (2001). Gestão da educação: o município e a escola. In N. Ferreira, \& M. A. Aguiar. (Orgs.), Gestão da educação: impasses, perspectivas e compromissos (3a ed.). São Paulo: Cortez.

Carneiro, M. H. da S. (2010). Trabalho docente e saberes experienciais. In I. P. A. Veiga, \& C. M. Q. Q. Viana. (Orgs.), Docentes para educação superior: processos formativos (pp. 101-113). Campinas: Papirus.

Casagrande, R. (2011). A avaliação institucional voltada às perspectivas estratégicas da instituição. In Colombo, S \& Rodrigues. G (Orgs.), Desafios da gestão universitária contemporânea (pp.219-243). Porto Alegre: Artmed.

Cunha, M. I. (1998). O professor universitário na transição de paradigmas. Araraquara: JM.

Dias, A. M. I. (2010). Leitura e (auto)formação: caminhos percorridos por docentes na educação superior. In I. P. Veiga, \& C. M. Q. Q. Viana (Orgs.), Docentes para educação superior: processos formativos (pp. 71-100). Campinas: Papirus.

Kanan, L. A., \& Zanelli, J. C. (2011). Envolvimento de docentes-gestores com o trabalho no contexto universitário. Psicologia \& Sociedade, 23(1), 56-65.

Leite, C., \& Silva, D. (1991). O desenvolvimento curricular no quadro das ciências da educação - gênese e estatuto. In Actas do $1^{\circ}$ Congresso da Sociedade Portuguesa de Ciências da Educação. Porto, Portugal.

Lopes Filho, J. (1992, julho/dezembro). A gestão compartilhada na escola. Revista Brasileira de Administração Educacional, 8(2), 8-33.

Luckesi, C.C. (2011). Avaliação da aprendizagem escolar: estudos e proposições (22a ed.). São Paulo: Cortez.

Maltez, J. A. (2003). Globalização: os novos ventos da história. Kulonga, 2, 93-100. 


\section{pro.posıções}

ISSN 1980-6248

Morin, P. (1997). A arte do gestor: da Babilônia à internet. Lisboa: Instituto Piaget.

Nosella, P. (2010). A escola e a cultura do desempenho. In Angela. Dalben, Julio. Diniz, Leiva. Leal, \& Luciola. Santos. Convergências e tensões no campo da formação e do trabalho docente (pp.37-56, Coleção Didática e Prática de Ensino). Belo Horizonte: Autêntica.

Paro, V. H. (1998). Gestão democrática da escola pública (2a ed.). São Paulo: Cortez.

Rámirez, G. (2011). Ensino Superior no mundo. In Colombo. S \& Rodrigues. G (Orgs.), Desafios da gestão universitária contemporânea (pp.23-42). Porto Alegre: Artmed.

Ramos, K. M. da C. (2010). Reconfigurar a profissionalidade docente universitária: um olhar sobre ações de atualização pedagógico-didática. Porto: Porto Editorial.

Sander, B. (2005). Políticas públicas e gestão democrática da educação. Brasília: Liber Livro.

Sousa, A. M. C. de. (2011). Gestão acadêmica atual. In Colombo. S., \& Rodrigues. G (Orgs.), Desafios da gestão universitária contemporânea (pp. 97-110). Porto Alegre: Artmed.

Veiga, I.P. A. (Org.). (1996). Projeto político da escola: uma construção possivel (2a ed.). Campinas: Papirus.

Zabalza, M. (2007). O ensino universitário, seu cenário e seus protagonistas. Porto Alegre: Artmed.

\section{Legislação}

Constituição da República Federativa do Brasil de 1988 (1988). Brasília: Presidência da República. Casa Civil. Subchefia para Assuntos Jurídicos.

Lei BR $n^{\circ}$ 9.394, de 20 de dezembro de 1996. Estabelece as diretrizes e bases da educação nacional. Diário Oficial da União, 20 de dezembro de 1996. Brasília: Presidência da República. Casa Civil. Subchefia para Assuntos Jurídicos.

Resolução CNE/CP n ${ }^{\circ}$, de 15 de maio de 2006. Institui Diretrizes Curriculares Nacionais para o Curso de Graduação em Pedagogia, licenciatura. Diário Oficial da União. Brasília, 16 de maio de 2006. Conselho Nacional de Educação.

Submetido à avaliação em 15 de julho de 2015; aceito para publicação em 18 de março de 2016. 
